\title{
Morphology Position
}

National Cancer Institute

\section{Source}

National Cancer Institute. Morphology Position. NCI Thesaurus. Code C117610.

The physical bearing of the body during a morphology assessment. 